\title{
CONSIDERATIONS OVER THE FLOATING SPEED OF A PARTICLE IN VACUUM PNEUMATIC CONVEYING SYTEMS IN FLOUR MILLING
}

\author{
Tanase TANASE ${ }^{1}$ \\ SC Tecnocereal SRL, Constanţa, Romania
}

\begin{abstract}
The present paper is a theoretical study aiming for to assess the influence of the different factors such as deviation from the spherical form of a particle, specific mass load of the pneumatic conveying pipe and the report between the particle diameter and the pipe diameter, over the floating speed of a particle. For a non-spherical particle, the Magnus force is affecting the floating speed of the given particle by increasing or decreasing it. The equation deducted within the present study, describes the movement of a particle or a fluid swirl under the resultant force with emphasis on the evaluation of the nature and magnitude of the Magnus force. The same Magnus Force explains the movement of the swirls in fluids, as for the wind swirls (hurricane) or water swirls. The next part of the study relate the report between the particle diameter and the pipe diameter as well as the specific loads of the pipe, to the same floating speed. A differentiation in denominating the floating speed is proposed as well as that for the non-spherical particle the floating speed should be a domain, rather than a single value.
\end{abstract}

Keywords: floating speed, pneumatic conveying, dilute phase

\section{INTRODUCTION}

Modern flour milling implies, undoubtedly, the pneumatic conveying of the intermediate stocks within the grinding section. Although this is highly used, the problem regarding the maximum efficiency of such a system in energy balance terms yet not clarified. The mixing ratio is the one that influence this balance; if this is not properly choose than a lot of energy is consumed just to transport air. The mixing ratio is the key element and it is connected to the floating speed of the product to be transported (Tanase, 2012).

\footnotetext{
1 Correspondent author. Correspondence address and actual working place: SC TECNOCEREAL SRL, str. Fagetului, nr. 136, Bloc ST3, Sc. F, Ap. 53, 900654-Constanţa, Romania, e-mail: tecnocereal@yahoo.com
} 
Experiments of a flow over a rotating cylinder has been carried out by Prandtl far back in 1925. In fluid mechanics, the problem of a particle in a flowing fluid (Gavrila, 2000) is one of the attempts that gives information of the basic of the floating phenomenon. The floating velocity, defined as "the velocity of an vertical air flow at which the particle floats", has been subject of many experiments, providing valuable information about the factors that influences the floating velocity as well as the magnitude of the floating velocity for the different types of intermediate stocks (Gerecke, 1991), (Costin, 1983) within the flour mills. All of these researches refers to the floating speed as for a single particle, or single kernel. None of them do not take into consideration the influence of the ratio between the particle diameter and the pipe diameter, nor the correlation between the specific load of the pipe and the floating speed. However, the problem is not yet cleared and the calculation of the in vacuum pneumatic conveying systems is still based on recommendations (Costin, 1983) and not on limit conditions.

The present study is an attempt to correlate the floating speed of a particle by the ratio between the diameter of particle and the specific load of the pipe. The influence of the Magnus force on the floating speed as well as its origin and magnitude are discussed.

\subsection{Flowing regime}

1.1.1. Flowing regime in the pipe. Reynolds number for the pipe.

Let consider two of the dimensional characteristics, namely:

- $\mathrm{d}$, diameter of the pipe, $[\mathrm{m}]$, in the specific range of the soft wheat flour milling usually being between $50 * 10^{-3}$ and $150 * 10^{-3}[\mathrm{~m}]$

- the speed of the air in the given pipe, in the specific range for the soft wheat flour milling being between 15 and $30[\mathrm{~m} / \mathrm{s}]$

Using known value for the kinematic viscosity $v$ for a known temperature of $15^{0} \mathrm{C}$ being as equal to $15,1 * 10^{-6}\left[\mathrm{~m}^{2} / \mathrm{s}\right]$ and using the above mentioned values for the maximum and minimum pipe diameter and air speed, we get Re between a $\mathrm{Re}_{\min }$ and $\mathrm{Re}_{\max }$ as follows (Florescu, 2007):

$$
\begin{aligned}
& R e_{\text {max }}=\frac{150 * 10^{-3} * 30}{15,1 * 10^{-6}}=298.000 \\
& R e_{\text {min }}=\frac{50 * 10^{-3} * 15}{15,1 * 10^{-6}}=49.670
\end{aligned}
$$

Reported to the pipe the flowing regime is always turbulent. It is considered that the limit of $\frac{1}{R e}$ goes to zero and the viscosity can be neglected.

\subsubsection{Flowing regime for the particle. Reynolds number for the particle}

Let consider two of the dimensional characteristics, namely:

- $d_{p}$, diameter of the particle, [m], in the specific range of the soft wheat flour milling usually being between $50 * 10^{-6}$ and $3.500 * 10^{-6}[\mathrm{~mm}]$ 
- the speed of the air. Due to the fact that the particle is in a floating condition, the speed of the air is precisely the floating speed of the particle. For the particles in subject, this should be between 5 and $9[\mathrm{~m} / \mathrm{s}]$, (Gerecke, 1991), (Meissner, 2008), (Costin, 1983).

$$
\begin{aligned}
& R e_{\text {max }}=\frac{3.500 * 10^{-6} * 9}{15,1 * 10^{-6}}=2.086 \\
& R e_{\text {min }}=\frac{50 * 10^{-6} * 5}{15,1 * 10^{-6}}=16,56
\end{aligned}
$$

For the floating state, the flowing regime reported to the particle remains laminar and that is allowing the lift force on the upper hemisphere to be present.

\subsection{Floating speed of a particle. Classical approach}

To study the particle balance in an air flow, one should consider the classic case of a spherical particle having a diameter $d_{p}$, located in a vertical air flow, into a pipe with a given diameter $d_{c}($ Figure 1$)$.

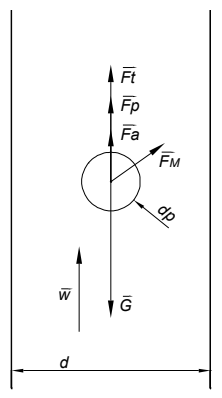

Figure 1. Forces acting on a particle in a vertical air flow

The forces acting on the particle are: Traction force (or resistance) generated in the lower hemisphere of the particle; Lift force, generated in the upper hemisphere of the particle; Archimedes Force; Magnus Force; Force of gravity. Assume all the other interactions between the particle and fluid, namely chemical, thermal or electrostatic interactions as void. By writing down the expressions of forces without taking into account Archimedes force (which has a very small value) and Magnus force (for, as it is shown later, it has an inconstant action for a free rotating non-spherical particle) and by extracting the floating speed, one find its classical expression (Klinzing et. al., 2010), (Costin, 1983) given by the equation below:

where:

$$
w=\sqrt{\frac{4}{3} \frac{d_{p}}{C_{d}} \frac{\rho_{p}}{\rho_{a}} g} \quad,[\mathrm{~m} / \mathrm{s}]
$$

$\mathrm{w}$-the floating speed of the particle that is the air velocity , $[\mathrm{m} / \mathrm{s}]$

$d_{p}, d-$ the diameter of the particle and the pipe diameter, [m]

$\mathrm{C}_{\mathrm{D}}$ - the drag coefficient that takes into account the skin friction and deviation from the spherical form of the particle, dimensionless 
$r_{p}, r_{a}-$ particle density, and air density, $\left[\mathrm{kg} / \mathrm{m}^{3}\right]$.

$\mathrm{g}$ - gravitational acceleration, $\left[\mathrm{m} / \mathrm{s}^{2}\right]$

In this equation, despite de reality of the phenomenon, the floating speed does not appear to be influenced by the relation between particle diameter and pipe diameter or by the amount of the flow of material.

\subsection{Floating speed of a particle. Fluid mechanics approach}

From dimensional analysis, is known that the drag coefficient is a function of the flowing regime (Klinzing et al., 2010), that flowing regime reported to the particle. Considering a spherical particle, which moves in a not bounded fluid, from the curve plotted for $\mathrm{C}_{\mathrm{d}}$ with respect to the Reynolds number, known as "Drag Coefficient Curve", for the Reynolds calculated for the particle we are in a transitory state, between Allen flow $\left(0,5<\mathrm{Re}_{\mathrm{p}}<500\right)$ and Newton flow $\left(500<\operatorname{Re}_{\mathrm{p}}<2 \times 10^{5}\right)$. Still, the flowing regime is laminar $\left(\operatorname{Re}_{\mathrm{p}}<2.320\right)$.

For the Newton flow regime, the drag coefficient is constant, about 0.44 . For Allen regime, a proposed equation (Gavrila, 2000) for to calculate the drag coefficient and to correlate de experimental data is the following:

$$
C_{d}=18,5\left(R e_{p}\right)^{-0,6} \text {, dimensionless }
$$

\section{PROPOSED APPROACH}

\subsection{Considerations about the forces acting on the particle}

2.1.1. Nature of the forces acting on the particle

In the following it is analyzed the expression of forces acting on the particle. On the whole, there are dynamics forces and gravitational forces, namely:

- Dynamics (pressure forces): traction force, lift force, Magnus force and Archimedes force

- Gravitational: the force of gravity

Dynamics forces:

Before proceeding to this evaluation, the general case of the link between force and pressure, namely that the force is equal to the pressure generated on a surface multiplied by the size of the surface, should be reminded:

$$
\vec{F}=\iint_{D} p * \vec{n} * d s=p * \vec{n} * S_{p}
$$

where:

$\mathrm{p}$ - is the static pressure generated over the particle surface, that particle surface of which inner normal vector is in the direction of the corresponding resultant force, $\left[\mathrm{N} / \mathrm{m}^{2}\right]$

$\mathrm{n}$ - the normal vector to the surface

$\mathrm{S}_{\mathrm{P}}-$ cross section area of the particle, $\left[\mathrm{m}^{2}\right]$

$\mathrm{D}$ - domain of the surface of the cross area of the particle 
By virtue of this law, all relevant forces in our case can be expressed as the result of the dynamic pressure of the fluid multiplied by the surface of particle cross section perpendicular to the direction of the fluid and multiplied by a correction factor.

where:

$$
F_{t}=\phi * S_{p} * p_{d}
$$

$\Phi-$ coefficient. It is $\xi$ for the traction (resistance) force, $C_{D}$ for the lift force and

$\mathrm{C}_{\mathrm{M}}$ for the Magnus force, dimensionless

$S_{p}$ - the area of the surface of particle cross section perpendicular to the direction of the air flow, $\left[\mathrm{m}^{2}\right]$. For Magnus Force, it is the area of the surface of particle cross section perpendicular to the line between two opposite points on the surface of the particle, considered on the same direction line $\mathrm{p}_{\mathrm{d}}$ - the dynamic pressure of the air flow, $\left[\mathrm{N} / \mathrm{m}^{2}\right]$

\subsubsection{Force of Magnus}

The less studied one is the Magnus force. According to some recent theoretical studies (Nedeff et. al., 2012), it is stated that the Magnus force determines a lifting (portent) force on the particle. Due the deviation from the spherical form, the Magnus Force affects the floating speed continuous and it's direction can be in decreasing the floating speed (lifting the particle), or increasing the floating speed (pushing downward), actually increasing the apparent weight of the particle.

Its direction continuous oscillates with the period of the particle rotation. Moreover, the Magnus force is the one responsible for the particle passage from one streamline to a next one. For to analyze the phenomenon, one shall consider a non-spherical particle positioned inside a vertical pipe of a diameter $d$ (figure 2). Before proceeding with the equations, one shall assume that:

- the surface of the particle is smooth, i.e. accepts in any given point representation of the normal, tangent and binormal vectors (it is derivative)

- the velocity vectors $\vec{A}$ and $\vec{B}$ are considered in the very vicinity of the reference points. According to the point 1.1.2., the flowing regime for the particle is steady and thus one can assume that these vectors are following the local profile of the particle surface

Due to the misalignment of the centers of the mass force and aerodynamic force, the particle will start to spin. Because of the local friction forces between the particle surface and the fluid, the spinning of the particle produce a change of the side velocities of the air flows: the $\vec{A}$ velocity will increase while the $\vec{B}$ velocity will decrease. The total local pressure for the each of the considered points being constant, the difference in the velocities will affect the static pressure for each of the considered points. 


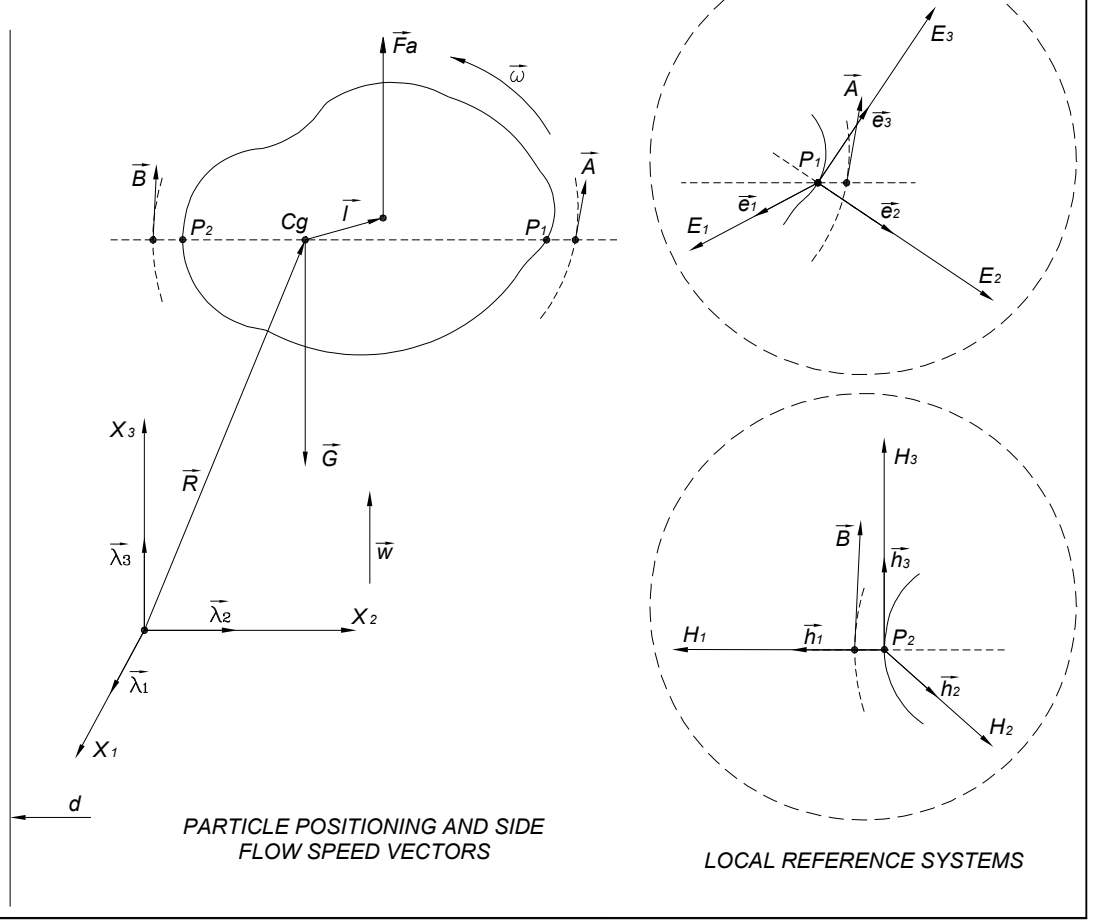

Figure 2. Particle positioning, local reference frames and side flow velocity vectors $\vec{A}$ and $\vec{B}$ of the fluid around particle; $\vec{w}$ - velocity of the air flow in the pipe, $[\mathrm{m} / \mathrm{s}]$; $\vec{G}$-weight force of the particle, $[\mathrm{N}]] ; \overrightarrow{F_{a}}$ - the sum of the aerodynamic forces on the particle acting in the pressure; center of the particle, [N]; P1, P2 - intersection point of the reference line with the boundary line of the particle cross section; $\mathrm{X}-$ main reference frame; E, $\mathrm{H}$ - local reference frames for the point $\mathrm{P} 1$ and $\mathrm{P} 2 ; \overrightarrow{\lambda_{r}}, \overrightarrow{e_{l}}$, $\overrightarrow{h_{J}}$ - unit vectors. For points $\mathrm{P} 1, \mathrm{P} 2$ : the tangent, normal and binormal; $\vec{A}$ and $\vec{B}-$ velocity of the fluid for the two reference points, $[\mathrm{m} / \mathrm{s}] ; \mathrm{Cg}-$ mass center of the particle; $\vec{R}$ - position vector of the particle, $[\mathrm{m}] ; \mathrm{d}$-pipe diameter, $[\mathrm{m}] ; \vec{r}-$ the distance between $\mathrm{P} 1$ and $\mathrm{P} 2,[\mathrm{~m}] ; \vec{\omega}$ - angular velocity of the particle, [rad/s].

From the total pressure equation, one can write:

$$
\Delta P_{s t}=\frac{1}{2} \rho\left(\vec{A}^{2}-\vec{B}^{2}\right)
$$

where:

$\mathrm{DP}_{\mathrm{st}}=\mathrm{P}$ - static pressure between considered points, $\left[\mathrm{N} / \mathrm{m}^{2}\right]$ $r-$ air density, $\left[\mathrm{kg} / \mathrm{m}^{3}\right]$

By the derivation by time and composition, we shall write:

where:

$$
\frac{d P}{d r} \frac{d r}{d R} \frac{d R}{d t}=\frac{1}{2} \rho \frac{d}{d t}\left(\vec{A}^{2}-\vec{B}^{2}\right)
$$

$\mathrm{dP} / \mathrm{dr}=\overrightarrow{-\nabla} P-$ pressure gradient between the considered points, $[\mathrm{Pa} / \mathrm{m}]$ 
$\mathrm{dr} / \mathrm{dR}=\mathrm{s}$, for a given moment, it is a number, dimensionless. At a given moment and position, this report (denoted as "s") is expressing the decreasing (contraction) or increasing (inflating) of the distance $\mathrm{r}$.

$\mathrm{dR} / \mathrm{dt}=\overrightarrow{v_{p}}$, velocity of the particle in the main reference frame $\mathrm{X},[\mathrm{m} / \mathrm{s}]$

By developing the expression $\frac{d}{d t}\left(\vec{A}^{2}-\vec{B}^{2}\right)$ one obtain:

and for each term one have:

$$
\frac{d}{d t}\left(\vec{A}^{2}-\vec{B}^{2}\right)=\frac{d}{d t}\left(\vec{A}^{2}\right)-\frac{d}{d t}\left(\vec{B}^{2}\right)
$$

$$
\frac{d}{d t}\left(\vec{A}^{2}\right)=\frac{d}{d t}(\vec{A} * \vec{A})=2 \vec{A} \frac{d \vec{A}}{d t}
$$

Analyzing the term $\frac{d \vec{A}}{d t}$, by composition (Gross, 2012), one can write (in the local reference frame E, fig. 2):

where:

$$
\frac{d \vec{A}}{d t}=\frac{d A_{i}}{d t} \overrightarrow{e_{l}}+A_{i} \frac{d \overrightarrow{e_{l}}}{d t}=a_{i} \overrightarrow{e_{l}}+A_{i} \frac{\partial \overrightarrow{e_{l}}}{\partial \varphi_{i}} \frac{\partial \varphi_{i}}{\partial s_{i}} \frac{d s_{i}}{d t}
$$

$\mathrm{A}_{\mathrm{i}}$ - the scalar component of the fluid velocity in the direction $\mathrm{i},[\mathrm{m} / \mathrm{s}]$ $\overrightarrow{e_{l}}$ - the unit vector in the direction $\mathrm{i}$

$\frac{d A_{i}}{d t}=\mathrm{a}_{\mathrm{i}}$-the scalar component of the fluid acceleration in the direction $\mathrm{i},\left[\mathrm{m} / \mathrm{s}^{2}\right]$ $\frac{\partial \varphi_{i}}{\partial S_{i}}=\mathrm{k}_{\mathrm{i}}^{\mathrm{A}}$ denoting the local curvature of the the particle profile (of the rank i) in

the direction $i$, equal to $1 / r_{A i}$, where $r_{A i}$ is the radius of curvature $\frac{\partial \overrightarrow{e_{l}}}{\partial \varphi_{i}}=\overrightarrow{e_{l+1}}-$ gives the next local unit vector, perpendicular to the unit vector $\overrightarrow{e_{l}}$, by rotating it with $+90^{\circ}$

Returning to the eq. (11) by the eq. (12) one can write:

$$
\frac{d}{d t}\left(\vec{A}^{2}\right)=2 \vec{A} \frac{d \vec{A}}{d t}=2 \vec{A}\left(a_{i} \overrightarrow{e_{l}}+A_{i} \frac{\partial \overrightarrow{e_{l}}}{\partial \varphi_{i}} \frac{\partial \varphi_{i}}{\partial s_{i}} \frac{d s_{i}}{d t}\right)
$$

and by using the expression: $\vec{A}=A_{i} \overrightarrow{e_{l}}$, in the local E reference frame, one shall obtain:

$$
\frac{d}{d t}\left(\vec{A}^{2}\right)=2 \vec{A} \frac{d \vec{A}}{d t}=2 a_{i} A_{i}
$$

Using the same algorithm for the $\vec{B}$ vector, and returning to the eq. (9) results:

$$
-\vec{\nabla} P * S * \overrightarrow{v_{p}}=\rho\left(a_{i} A_{i}-b_{j} B_{j}\right)
$$

Where $\mathrm{j}$ stands for the local reference frame $\mathrm{H}$ (fig. 2), for the considered point $\mathrm{P}_{2}$, for the vector $\vec{B}$. By translating each of the vectors $\vec{A}$ and $\vec{B}$ in the main reference frame $X$, by tensorial transformation, one shall have:

$$
-\vec{\nabla} P * S * \overrightarrow{v_{p}}=\rho\left(a_{i} A_{i} \frac{\partial a_{i}^{r}}{\partial a_{i}} \frac{\partial A_{i}^{r}}{\partial A_{i}}-b_{j} B_{j} \frac{\partial b_{j}^{r}}{\partial b_{j}} \frac{\partial B_{j}^{r}}{\partial B_{j}}\right)
$$

The eq. (16) shows that for a non-spherical particle, the side force, namely Magnus Force, is influencing the floating speed of the given particle. Due to continue changing of the direction and of the magnitude of this force, the 
influence could be either in the direction of increasing the floating speed or decreasing the floating speed of the particle. This phenomenon can be easy observed for the particles coming from the shell side of a cereal kernel that makes ascending spiral movements when in a vertical air flow (figure 3 ). The right term of the eq. (16) actually gives the specific power consumed in the fluid, between the two points considered, as $\left[\mathrm{watt} / \mathrm{m}^{3}\right]$ of fluid. Also, for the non-spherical particle, due to the variation of the pressure gradient vector, the acceleration of the particle is not constant. If the considered particle is not a solid one but a rotating portion of a fluid inside the same fluid, then the eq. 16 will predict the displacement and the trajectory of the resulting fluid swirl. The phenomenon is obvious for the wind swirls (hurricane) that, for example, in the north hemisphere (counter-clock rotation), due to the Coriolis effect will always move north-west describing a curve. Similar phenomenon for the south wind swirls (clock rotation). More, the eq. 16 explain the vertical bending of a fluid swirl. For a particle that is closing the inner side of the pipe wall, due to the turbulent flowing regime in the pipe, it can be observed in a pneumatic pipe that these are immediately repealed and aligned with the center line of the pipe, while accelerating (fig. 4). This is because the speed of the air between the particle and the inner wall of the pipe is decreasing (wall friction of the air flow in the pipe) and due to this, the static pressure on that side of the particle is increasing (reversing the action of the pressure gradient).

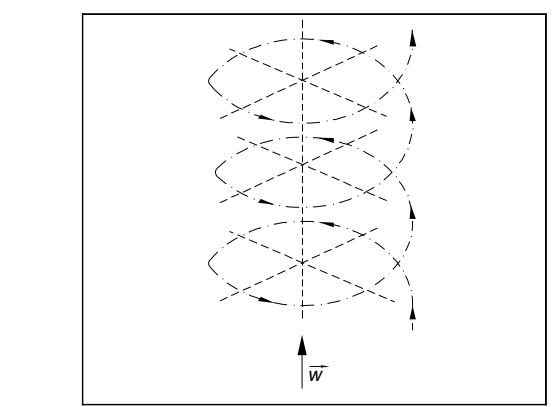

Figure 3. Non-spherical particle movement in pipe

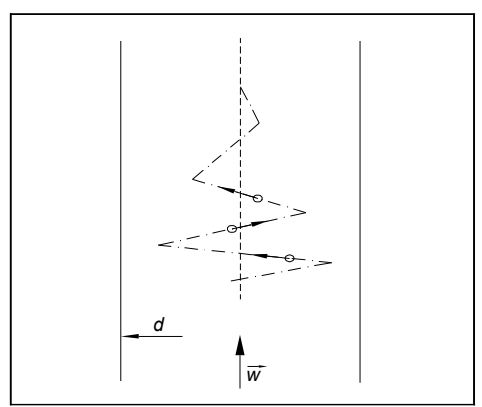

Figure 4. Particle movement when approaching the inner wall of the pipe

For a perfect spherical particle, the pressure gradient will be constant for constant conditions, while the direction of the Magnus force will be perpendicular to the center line of the pipe, through the center of mass of the particle, considering again the pipe as being vertical. In this case, the Magnus force itself, does not influence the floating speed of the particle.

\subsection{Considerations over the particle dimension and specific load}

\subsubsection{The ratio between particle diameter and the pipe diameter}


A spherical material particle having the diameter $d_{p}$, has a certain floating speed. This floating speed, determined in the free atmosphere will have a certain value. By repeating the measurement of the floating speed for the same particle (by keeping all other conditions unchanged) in a pipe with a diameter $\mathrm{d}$ with $\mathrm{d}>>\mathrm{d}_{\mathrm{p}}$, one shall find that the floating speed thus determined will have a lower value. Further on, one shall find that as the ratio between the particle diameter and the pipe diameter increases, the floating speed decreases.

Returning to the case of Figure 1, corresponding to the pipe diameter $d$ and air speed w, we have a volumetric flow of air. Working speeds are less than $1 / 3$ of the speed of sound in the air and therefore one can consider the density as constant (as stated at point 1.1.1., the report $\frac{1}{R e}$ is going to zero and one can neglect the viscosity). In these conditions, of the balance equations of the volumetric flow written for two situations:

- in a point of a free cross section of the pipe, free of particle

- in a point of the cross section of the pipe, between the particle and the pipe

- and since $\frac{\partial \rho}{\partial x_{i}} \frac{\partial x_{i}}{\partial t}=0$, the fluid is homogenous

, it follows:

where:

$$
w=\frac{d^{2}-\sum_{i=1}^{n} d_{i}^{2}}{d^{2}} w_{e}
$$

$\mathrm{w}$ - air velocity in a point of cross section of pipe, free of particle, $[\mathrm{m} / \mathrm{s}]$

$\mathrm{W}_{\mathrm{e}}-$ air velocity in a point of the cross section, between particle and pipe, $[\mathrm{m} / \mathrm{s}]$.

It is actually the floating speed of the particle and it is the one that generates all aerodynamic forces.

$d_{i}-$ the equivalent diameter of the free area of the all cross sections of the particles considered in a cross section of a pipe, [m]

$\mathrm{n}$ - stands for the number of particles cross sectioned

\subsubsection{Amount of the mass flow of material. Specific load of the pipe}

Another factor influencing the floating speed is the amount of the mass flow of material to be conveyed. It can be easily found that when the material flow exceeds the carrying capacity of the column, it gets clogged, namely the pneumatic conveying can no longer take place. In fact, an increase of the floating speed of the product in the pipe occurs up to a value when the energy intake of the fan is outrun. In equation (1) for the force of gravity it was used the classical writing.

Considering the fact that there is a dynamic regime and there is a constant flow of product $\mathrm{q}_{\mathrm{m}}$, one can write the particle mass from the force of gravity equation as the result of the specific loading of the pipe (Tanase, 2014), multiplied by the pipe cross section. For the area of the cross section of the 
particle, we shall consider the sum of the all cross sections areas of the particles $\mathrm{n}$ within the considered cross section of the pipe.

As it is mentioned above, for a constant flow of material $\mathrm{q}_{\mathrm{m}}$ and for a pipe diameter $\mathrm{d}$, one can define the specific loading $\mathrm{q}_{\mathrm{s}}$ of the pipe as:

where:

$$
q_{s}=\frac{q_{m}}{s_{c}},\left[\mathrm{kgproduct} / \mathrm{m}^{2} \text { sectionpipe } / \mathrm{s}\right],
$$

$\mathrm{q}_{\mathrm{m}}$ - the product flow to be transported, [kgproduct/s]

$\mathrm{S}_{\mathrm{c}}-$ cross section are of the pipe, $\left[\mathrm{m}^{2}\right]$

In the floating speed equation, for the definition of the force of gravity, one shall consider that the mass of the particle is actually the total mass of all particles at a given time in one section of the pipe. Also, the surface of the particle cross section will be considered as the sum of cross sections of all particles in the considered cross section of the pipe. Therefore, the diameter of the cross section of one given particle will be denoted as $d_{i}$, since this one can vary between zero and $d_{p}$, that is the maximum diameter of the particle.

\section{INTERPRETATION OF THE APPROACH}

\subsection{Nature of velocity}

In section 2.2.1. the notion of effective speed of air flow $\mathrm{w}_{\mathrm{e}}$ was introduced, that is the actual speed at which the air flow generates the forces acting on the particle. This has a different value than the air speed $w$ measured in a free section of the pipe. The actual speed is the one determining the measure of forces acting on the particle and is directly related to the ratio $d_{p} / d$. In virtue of this statement, one ought therefore to dissociate the two speeds and should call it: Actual floating speed, $\mathrm{w}_{\mathrm{e}},[\mathrm{m} / \mathrm{s}]$; Floating speed associated to the pipe of diameter d, namely $\mathrm{w},[\mathrm{m} / \mathrm{s}]$.

For the same particle and for identical working conditions, one shall obtain, for different pipe diameters, different floating speeds. Each of these speeds will be specific to the pipe which has been determined and will be unique to that particle, namely for ratio $d_{p} / d$.

\subsection{Resulting equation for the floating speed.}

Rewriting the equation (1) of the balance of forces, this time considering Archimedes force, but in the mass expression in the force of gravity replace the mass with the result of the specific load of the pipe multiplied by the pipe section, one obtain the equation that defines the actual floating speed and includes the influence of product flow:

where:

$$
w_{e}=\sqrt{2 g \frac{3 d^{2} q_{s}-2 d_{p}^{3} n \rho_{a}}{3 \varphi\left(\sum_{i=1}^{n} d_{i}^{2}\right) n \rho_{a}}}
$$


$\phi-$ sum of the coefficients $\xi$ for traction force, lift coefficient $C_{D}$ and Magnus force coefficient $\mathrm{C}_{\mathrm{M}}$, dimensionless

$\mathrm{n}$ - number of particles considered, $[1 / \mathrm{s}]$

$\mathrm{d}_{\mathrm{i}}$ - the equivalent diameter of the cross section area of all particles in the considered cross section of the pipe, $[\mathrm{m}]$

By replacing in equation (17) the actual floating speed $\mathrm{w}_{\mathrm{e}}$ with its expression given by equation (19), one obtain the floating speed associated to the pipe in question:

$$
w_{a}=\left(1-\frac{\sum_{i=1}^{n} d_{i}^{2}}{d^{2}}\right) \sqrt{2 g \frac{3 d^{2} q_{s}-2 n d_{p}^{3} \rho_{a}}{3 \varphi n d_{p}^{2} \rho_{a}}} \quad,[\mathrm{~m} / \mathrm{s}]
$$

\section{CONCLUSIONS}

The influence of the ratio $d_{p} / d$ is a known fact in pneumatic conveying. The introduction of the ratio $d_{p} / d$ in the floating speed of a particle equation has been proposed as a formula for approximating the floating speed of a particle by V.A. Uspenski (Bulat, 1962).

The equation of the floating speed of a particle in a vertical air flow deducted in this paper (eq. 20) incorporates both the influence of the ratio between particle diameter and pipe diameter and the influence of the load with product of the pipe on it. For a pipe with a diameter which tends to infinity, namely in case of an open atmosphere, the equation gives the actual maximum floating speed or the limit speed for falling in quiet atmosphere.

Within milling units, for the calculation of pneumatic conveying systems especially in the grinding department it is therefore preferable, where reasonable to use, for the same grinding passage, multiple columns instead of one. This results in the lowering of the value of the actual floating speed of product concerned and in superior energy efficiency of the system.

The floating speed depends by the loading ratio of the pipe, but for the same load it still differs because of the different number of particles. For a specific grinding passage, it is therefore preferable to have a higher grinding degree.

For the non-spherical particles the floating speed actually oscillates between a maximum value (that corresponds to a maximum magnitude of the projection of Magnus Force in the downward direction) and a minimum value (that corresponds to a maximum magnitude of the projection of Magnus Force in the upward direction). Thereby, when separation of two solid fraction with close floating speed is to be made, would be recommended to calibrate the dimensions of the particle before separation takes place, by grinding and sifting/calibrating the particles from the mixture.

Therefore, a concrete value for the floating speed could actually be defined only for spherical particles, while for the non-spherical particles it should be a 
domain. For a horizontal pneumatic conveying pipe, the Magnus force affects the floating speed, no matter the particle is spherical or not.

\section{REFERENCES}

1. Gerecke K. H. ( 1991). Technische Werte der Getraideverarbeitung und Futtermitteltechnick - Teil 3: Fordertechnick. Detmold, Germany: Verlag Moritz - Schafer

2. Meissner, W. ( 2008). Fordertechnick in Silo und Muhle. Agrimedia Gmbh, Handbuch Mehl - und Schalmullerei ( pp. 61-92) . Clenze, Germany: Erling Verlag GmbH \& Co.

3. Costin, I. (1983). Tehnologii de Prelucrare a Cerealelor in Industria Moraritului. Bucuresti: Editura Tehnica

4. Klinzing, G. (2009). Historical Review of Pneumatic Conveying and Solids Processing World Wide. Pittsburgh AIChE Paper, University of Pittsburgh, Retrieved November 2012: http://www.engineering.pitt.edu/GeorgeKlinzing/

5. Bulat, A. (1962). Instalatii de Transport Pneumatic. Bucuresti: Editura Tehnica

6. Klinzing G. E., Rizk F., Marcus R. \& Leung L.S. (2010). Pneumatic Conveying of Solids - A Theoretical and Practical Approach, third edition. London, England: Springer Dordrecht Heidelberg London.

7. Tanase, T (2012). Cercetari Privind Eficientizarea Transportului Pneumatic in Industria Moraritului. Sibiu: Universitatea "Lucian Blaga" (MECTS, 6149/07.11.2012), $\mathrm{PhD}$ thesis

8. Tănase, T. (2012). Defining of the limit condition for the in-vacuum dilute phase pneumatic conveying systems - Clogging Constant. Acta Universitatis Cibiniensis, series E: Food Technology, Vol. XVI, no. 2, ISSN 1221-4973, 3342

9. Eck, B. (2003). Ventilatoren.Entwurf un Betrieb der Radial-, Axial- und Querstromventilatoren. Berlin: Verlag Springer

10. Tănase, T. (2014). Regime mixing ratio for the in-vacuum dilute phase pneumatic conveying systems. Acta Universitatis Cibiniensis, series E: Food Technology, Vol. XVIII, no. 1, ISSN 1221-4973, 33-46, Universitatea "Lucian Blaga", Sibiu, 2014

11. Gross, Herbert (2012). Part I: Vector Arithmetic|MIT Calculus Revisited: Multivariable Calculus, Published on Mar 12, 2012, Retrieved August 2015, http://ocw.mit.edu/RES18-007F11

12. Florescu, I. (2007). Mecanica Fluidelor. Note de curs pentru uzul studentilor. Bacau: Editura Alma Mater

13. Nedeff V., Mosnegutu E., Panainte M., Ristea M., Lazar G., Scurtu D., Ciobanu B., Timofte A., Toma S., Agop M., (2012). Dynamics in the boundary layer of a flat particle. Powder Technology, Volume 221 (2012), 312-317

14. Gavrila, L. (2000). Fenomene de transfer. Vol 1. Transfer de impuls. Bacau: Editura Alma Mater 